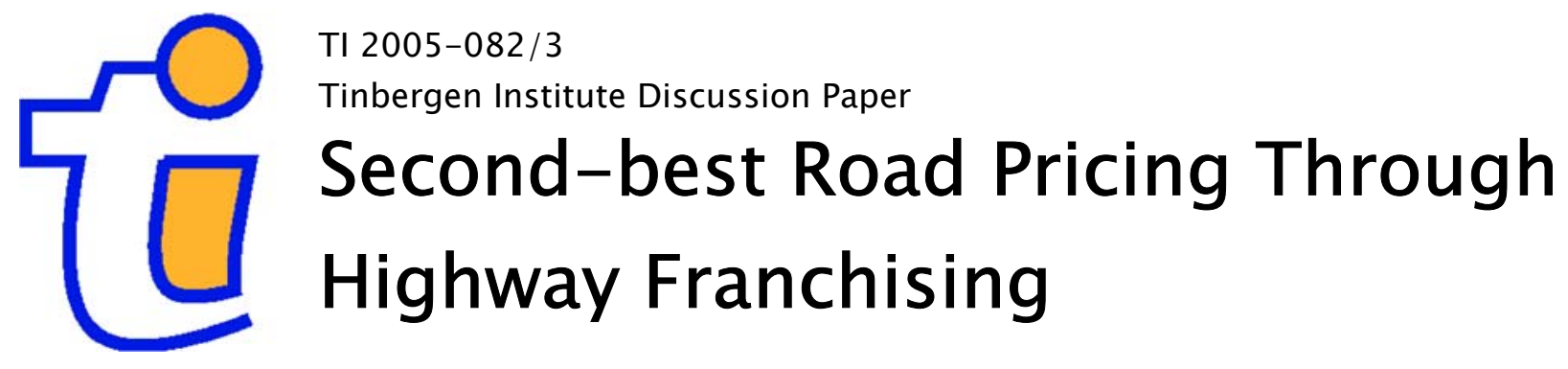

Erik Verhoef

Department of Spatial Economics, Free University Amsterdam, and Tinbergen Institute. 


\section{Tinbergen Institute}

The Tinbergen Institute is the institute for economic research of the Erasmus Universiteit Rotterdam, Universiteit van Amsterdam, and Vrije Universiteit Amsterdam.

Tinbergen Institute Amsterdam

Roetersstraat 31

1018 WB Amsterdam

The Netherlands

Tel.: $\quad+31(0) 205513500$

Fax: $\quad+31(0) 205513555$

Tinbergen Institute Rotterdam

Burg. Oudlaan 50

3062 PA Rotterdam

The Netherlands

Tel.: $\quad+31(0) 104088900$

Fax: $\quad+31(0) 104089031$

Please send questions and/or remarks of nonscientific nature to driessen@tinbergen.nl.

Most TI discussion papers can be downloaded at http://www.tinbergen.nl. 


\title{
SECond-Best RoAd Pricing Through Highway FRANCHISING
}

\author{
Erik T. Verhoef \\ Department of Spatial Economics \\ Free University Amsterdam \\ De Boelelaan 1105 \\ 1081 HV Amsterdam \\ The Netherlands \\ Phone: +31-20-4446094 \\ Fax: +31-20-4446004 \\ Email: everhoef@econ.vu.nl
}

This version: 12/08/05

Key words: Traffic congestion, second-best pricing, highway franchising

JEL codes: R41, R48, D62

\begin{abstract}
This paper considers the welfare impacts of a range of franchising regimes for congestible highways. For a single road in isolation, it is shown that a competitive auction with the level of road use as the decision criterion produces the socially optimal road (in terms of capacity and toll level) as the equilibrium outcome, provided constant returns to scale characterize highway operations. The auction outperforms various alternatives, in which the bidders are asked to minimize the toll level or toll revenues, or to maximize capacity or the bid for the franchise. When second-best network aspects are taken into account, the patronagemaximizing auction is no longer optimal. When unpriced congestion on parallel capacity dominates, the second-best highway would generate losses and the zero-profit condition becomes binding. The auction produces a below-optimal capacity. When unpriced congestion on serial capacity dominates, the auction produces an above-optimal capacity.
\end{abstract}

*Affiliated to the Tinbergen Institute, Roetersstraat 31, 1018 WB Amsterdam. 



\section{Introduction}

The private supply of highway capacity offers one way to deal with growing traffic congestion in the face of insufficient public funds to finance new capacity, and insufficient support for public road pricing. Private involvement in highway supply is not exceptional. Around one-third of the Western European highway network is currently under concession, with a strong concentration in the more Southern countries of France, Spain, Italy and Portugal. Some of the value pricing projects in the US involve private pay-lanes. And private toll roads are an increasingly common phenomenon in developing countries.

Proclaimed potential advantages of private over public highways include costefficiency, innovativeness, and availability of funds. A main disadvantage is the divergence between the private objective of profit maximization and the social objective of welfare maximization (e.g. Edelson, 1971; Mills, 1981; Mohring, 1985). An important question is whether there are ways, particularly through the design of auctions for highway concessions, to make the private operator behave more closely in line with welfare maximizing price and capacity setting. Such strategies might preserve the advantages of private involvement, while limiting the potential disadvantages. Moreover, a properly designed auction would provide incentives to minimize the cost of supplying the capacity chosen, and would give the government an objective way to select a road operator among a larger set of candidates. And finally, the use of auctions or comparable allocation mechanisms seems unavoidable in the awarding of concessions for highways, anyway. It is therefore important to have a proper understanding understand of the potential efficiency impacts of the design of such auctions.

This paper investigates one particular aspect of auctions for highway concessions, namely the extent to which the choice of the criterion used in the selection of the winning bid affects the efficiency of the resulting highway. We will mainly consider auctions in which private bidders are free to select highway capacity and toll, but will briefly consider more limited auctions as well. To focus attention, a number of simplifying assumptions will be made. First, we consider stationary traffic conditions with homogeneous users. Second, we ignore specific distortions that might arise from strategic interactions between bidders in the auction by considering competitive auctions only. There is no a priori reason to expect that these interactions would systematically affect the ranking of the various criteria that we will consider, although the welfare gains (or losses) from each criterion would of course be different under non-competitive bidding. Third, we will not formally model demand uncertainty and contract renegotiation. And fourth, we will assume that the government has sufficient power and credibility to enforce fulfilment of the bid, and can punish violations such that the net profitability of winning the auction but not living up to it would be negative and hence below that of not winning. The set-up of the analysis is similar to that of Ubbels and Verhoef (2004), but extends it by considering the impacts of an unpriced complement (in addition to an unpriced substitute); by considering as candidate criteria maximum patronage and, for pre-specified capacities, minimum toll revenues; and by using a different (non-linear, BPR-type) congestion cost function in the numerical model. 
The plan of the paper is as follows. Section 2 starts with some theoretical backgrounds. Section 3 considers a single road, while Section 4 moves on to introduce network aspects. Section 5 concludes.

\section{Theoretical backgrounds}

This section provides some theoretical backgrounds for our analysis. Section 2.1 identifies the conditions for surplus-maximizing and profit-maximizing road capacities and tolls, and thus identifies the direction in and extent to which an auction should ideally affect the private operator's choices, compared to unrestricted freedom in setting the toll and capacity. Three cases are discussed: the benchmark of an isolated road, and two second-best cases allowing for simple network spill-overs, namely where either an unpriced substitute or an unpriced complement is available. Section 2.2 addresses the profitability of surplus-maximizing roads, and therewith identifies the desirability for auctions designed so as to push bidding companies to a zero-profit bid.

\subsection{Welfare maximizing and profit maximizing tolls and capacities}

\section{Single road}

Consider a single road with capacity $K$, which is used under stationary traffic conditions by homogeneous drivers with an aggregate inverse demand function $D(N)$, where $N$ denotes the equilibrium flow of traffic. The average user cost includes all variable costs incurred by the user, including travel time, and depends, through congestion, on $N$ and $K$. It is denoted $c(N, K)$. The generalized price faced by road users, $p(N, K)$, is equal to the sum of $c(N, K)$ and a toll $\tau$ if levied. The per-unit-of-time capacity cost depends on the road's capacity and is denoted $C^{c}(K)$. Ignoring external costs other than congestion, the first-best optimal toll and capacity, defined so as to maximize social surplus, can be determined by solving the following Lagrangian:

$\Lambda=\int_{0}^{N} D(n) \mathrm{d} n-N \cdot c(N, K)-C^{c}(K)+\lambda \cdot(c(N, K)+\tau-D(N))$

where the first three terms represent the objective, and the fourth term the equilibrium constraint ( $\lambda$ is the Lagrangian multiplier). The set of first-order conditions (w.r.t. $N, K, \tau$ and $\lambda)$ can be solved to yield two familiar conditions:

$\tau=N \cdot c_{N}$

$-N \cdot c_{K}=C_{K}^{c}$

where subscripts denote partial derivatives. Equation (2a) shows that the optimal toll should be set equal to the marginal external congestion costs, while ( $2 b$ ) shows that the marginal benefits of capacity expansion (the 1.h.s.) should be equal to the marginal cost (the r.h.s.).

An unrestricted private road operator would maximize profits by solving: 
$\Lambda=N \cdot \tau-C^{c}(K)+\lambda \cdot(c(N, K)+\tau-D(N))$

The set of first-order conditions now yield:

$$
\begin{aligned}
& \tau=N \cdot c_{N}-N \cdot D_{N} \\
& -N \cdot c_{K}=C_{K}^{c}
\end{aligned}
$$

The profit-maximizing toll includes the marginal external congestion costs from (2a), but adds to this a standard monopolistic mark-up that increases as demand becomes less elastic. The latter term has the conventional interpretation; the internalization of congestion is motivated by the fact that any reduction in congestion costs can be turned into revenues for the operator by increasing the toll accordingly. Internalizing the congestion externality therefore contributes to the profit.

Interestingly, the profit-maximizing optimality condition for capacity choice (4b) is the same as for the social optimum (2b). The reason is that for a given $N$, the operator can turn savings in average user costs into toll revenues on a Euro-by-Euro basis when increasing capacity. The profit-maximizing trade-off is therefore identical to the surplus-maximizing trade-off. Of course, the difference between (2a) and (2b) will generally cause the profitmaximizer to evaluate (4b) for a smaller $N$ than a surplus-maximizer would consider, producing a lower optimal capacity. As a corollary, when demand is perfectly elastic so that (4a) becomes equal to (2a), a profit-maximizing operator would set its instruments such that the optimum is achieved, and no further regulation is warranted. Because estimates of demand elasticity for road transport usually indicate elasticities well below -1 (in absolute terms), this observation is of very limited use for practical policy making.

Under first-best pricing and capacity choice, equations (2a) and (2b) would hold for every single link in a network. And a private operator would attempt to add to this a monopolistic mark-up, as in (4a), for every origin-destination pair in the network. Indeed, network extensions become more challenging analytically when second-best conditions apply elsewhere on the network. An important type of second-best distortion would be the existence of untolled, congested links, with capacities set arbitrarily. Solving the resulting second-best optimal or revenue-maximizing tolls and capacities can yield tedious expressions (see Verhoef, 2002ab) that elude easy interpretation. More insightful expressions can be obtained by considering two particular extensions of the one-link network considered above: one with an unpriced parallel link (a substitute), and one with an unpriced serial link (a complement).

\section{Unpriced substitute}

The case of second-best congestion pricing with an unpriced substitute has been considered by various authors, including Lévy-Lambert (1968). The inclusion of capacity as a second policy instrument has been less common. Using superscripts $U$ and $T$ to denote the untolled and the tolled alternative, respectively, and assuming that $K^{U}$ is to be treated as given, the 
surplus-maximizing second-best toll $\tau^{T}$ and capacity $K^{T}$ can be found by solving the following Lagrangian:

$$
\begin{aligned}
\Lambda= & \int_{0}^{N^{U}+N^{T}} D(n) \mathrm{d} n-N^{U} \cdot c^{U}\left(N^{U}, K^{U}\right)-N^{T} \cdot c^{T}\left(N^{T}, K^{T}\right)-C^{c, U}\left(K^{U}\right)-C^{c, T}\left(K^{T}\right) \\
& +\lambda^{U} \cdot\left(c^{U}\left(N^{U}, K^{U}\right)-D\left(N^{U}+N^{T}\right)\right)+\lambda^{T} \cdot\left(c^{T}\left(N^{T}, K^{T}\right)+\tau^{T}-D\left(N^{U}+N^{T}\right)\right)
\end{aligned}
$$

The set of first-order conditions (w.r.t. $N^{U}, N^{T}, K^{T}, \tau^{T}, \lambda^{U}$ and $\lambda^{T}$ ) can be solved to yield:

$$
\begin{aligned}
& \tau^{T}=N^{T} \cdot c_{N^{T}}^{T}-N^{U} \cdot c_{N^{U}}^{U} \cdot\left(\frac{-D_{N}}{c_{N^{U}}^{U}-D_{N}}\right) \\
& -N^{T} \cdot c_{K^{T}}^{T}=C_{K^{T}}^{c, T}
\end{aligned}
$$

where $D_{N}$ denotes the slope of the (single) demand function.

The second-best optimal toll (6a) is the same as the one reported by Lévy-Lambert (1968), and is therefore unaffected by the possibility of also setting capacity for route $T$. A more detailed interpretation of this toll expression can be found in Verhoef et al. (1996), but note that it is below the marginal external congestion on route $T$ in order to optimize the congestion spill-over onto route $U$. The second-best optimal capacity rule (6b) is similar to the first-best rule (2b). Given the equilibrium level of use of route $T, N^{T}$, and given the associated generalized equilibrium price $c^{T}+\tau^{T}$, it is optimal to set capacity $K^{T}$ such that the flow $N^{T}$ is served at a combination of $K^{T}$ and $\tau^{T}$ that minimizes the social cost of carrying $N^{T}$. The optimality condition for capacity is therefore the same as for a road without substitute.

The profit-maximizing toll and capacity follow from:

$$
\begin{aligned}
\Lambda= & N^{T} \cdot \tau^{T}-C^{c, T}\left(K^{T}\right) \\
& +\lambda^{U} \cdot\left(c^{U}\left(N^{U}, K^{U}\right)-D\left(N^{U}+N^{T}\right)\right)+\lambda^{T} \cdot\left(c^{T}\left(N^{T}, K^{T}\right)+\tau^{T}-D\left(N^{U}+N^{T}\right)\right)
\end{aligned}
$$

The set of first-order conditions (w.r.t. $N^{U}, N^{T}, K^{T}, \tau^{T}, \lambda^{U}$ and $\lambda^{T}$ ) now yields:

$$
\begin{aligned}
& \tau^{T}=N^{T} \cdot c_{N^{T}}^{T}-N^{T} \cdot D_{N} \cdot\left(\frac{c_{N^{U}}^{U}}{c_{N^{U}}^{U}-D_{N}}\right) \\
& -N^{T} \cdot c_{K^{T}}^{T}=C_{K^{T}}^{c, T}
\end{aligned}
$$

The same tax rule can be found in Verhoef, Nijkamp and Rietveld (1996) in which $K_{T}$ is held fixed, and it is therefore again not affected by the possibility to set capacity. Note that, in contrast to the second-best toll in (6a), this tax rule adds a positive term to the common firstterm (that represents the marginal external congestion cost on the tolled route). As we found for the single link, the optimality conditions for surplus-maximizing and profit-maximizing capacity, (6b) and (8b), are the same. The chosen capacities will differ only because the point of evaluation differs. 


\section{Unpriced complements}

Second-best pricing with an unpriced complement (such as a serial link) has received considerably less attention in the literature than the unpriced substitute. Maintaining the assumptions of a single origin-destination pair and control over instruments at one of the two links only, the second-best optimum is easily found by adapting (5) to the new network configuration that implies that the same users use link $U$ and $T$ :

$$
\begin{aligned}
\Lambda= & \int_{0}^{N} D(n) \mathrm{d} n-N \cdot c^{U}\left(N, K^{U}\right)-N \cdot c^{T}\left(N, K^{T}\right)-C^{c, U}\left(K^{U}\right)-C^{c, T}\left(K^{T}\right) \\
& +\lambda \cdot\left(c^{U}\left(N, K^{U}\right)+c^{T}\left(N, K^{T}\right)+\tau^{T}-D(N)\right)
\end{aligned}
$$

The set of first-order conditions (w.r.t. $N, K^{T}, \tau^{T}$, and $\lambda$ ) can be solved to yield:

$$
\begin{aligned}
& \tau^{T}=N \cdot\left(c_{N}^{T}+c_{N}^{U}\right) \\
& -N \cdot c_{K^{T}}^{T}=C_{K^{T}}^{c, T}
\end{aligned}
$$

Intuitively, the second-best optimal toll perfectly internalizes the marginal external congestion costs for both links jointly. The rule that defines optimal capacity has the by now familiar form. Again no effects on link $U$ are present in this rule, which reflects that indirect effects of changes in $K^{T}$ upon congestion on link $U$ cancel because the toll in (10a) already perfectly internalizes this congestion.

Finally, the profit-maximizing choice of instruments can be found from solving:

$$
\Lambda=N \cdot \tau^{T}-C^{c, T}\left(K^{T}\right)+\lambda \cdot\left(c^{U}\left(N, K^{U}\right)+c^{T}\left(N, K^{T}\right)+\tau^{T}-D(N)\right)
$$

The set of first-order conditions (w.r.t. $N, K^{T}, \tau^{T}$, and $\lambda$ ) now yields:

$$
\begin{aligned}
& \tau^{T}=N \cdot\left(c_{N}^{T}+c_{N}^{U}-D_{N}\right) \\
& -N \cdot c_{K^{T}}^{T}=C_{K^{T}}^{c, T}
\end{aligned}
$$

The profit-maximizing toll is a straightforward generalization of (4a), like the surplusmaximizing toll (10a) was from (2a). And also in this final network, the rule dictating profitmaximizing capacity is the same as the one for surplus maximization. The chosen capacities will again differ only because the point of evaluation differs.

\subsection{Optimality, self-financing and maximized profits}

A famous result from the transport economics literature, derived by Mohring and Harwitz (1962), states that an optimally designed road - i.e., with an optimal capacity and an optimal toll - will be exactly self-financing, provided some technical conditions are satisfied. These technical conditions can be summarized as follows: (1) road capacity should be a continuous variable; (2) there should be constant returns to scale in congestion technology (equiproportional changes in use and capacity leave average user cost unaffected); and (3) there 
should be constant economies of scale in highway construction (the cost per unit of capacity is independent of total capacity). This 'self-financing' theorem has been shown to extend to each road individually in a full network, and therefore also to the network in aggregate, provided each link is optimally priced and all capacities are optimized (Yang and Meng, 2002). The theorem also extends to dynamic models (Arnott, De Palma and Lindsey, 1993); and in present-value terms when allowing for adjustment costs and depreciation (Arnott and Kraus, 1998).

Empirical evidence suggests that conditions (2) and (3) may hold at least approximately: empirical estimates of the ratio of long-run average and marginal costs are often relatively close to unity (Small, 1992, Sections 3.4, 3.5). ${ }^{1}$ Profits or deficits under optimal design and pricing of a road will then be relatively small. Condition (1) seems unrealistic for a single road because the number of lanes is discrete. But capacity per lane can be varied by widening lanes, by resurfacing, or by re-grading or straightening a stretch of road. And when this is not the case, an optimally designed road might still be self-financing over the longer run, when periods of undercapacity and overcapacity alternate as demand grows over time.

We can illustrate the self-financing theorem in our model by replacing the general cost function $c(N, K)$ by the somewhat more specific $c(N / K)$ (securing constant returns in congestion technology), and the capacity cost function $C^{c}(K)$ by $\mathcal{\gamma} \cdot K$, with $\mathcal{\gamma}$ denoting a constant cost per unit of capacity (securing constant economies of scale in highway construction). Observe that:

$$
\frac{\partial c(N / K)}{\partial K} \equiv-\frac{N}{K} \cdot \frac{\partial c(N / K)}{\partial N}
$$

All conditions for optimal capacity choice encountered thus far were of the same type, which can be rewritten (using our assumption of a constant cost per unit of capacity) as:

$$
-N \cdot c_{K}=\gamma^{c}
$$

Multiplying both sides by $K$ yields:

$-K \cdot N \cdot c_{K}=C^{c}$

or, using (13a):

$$
N \cdot N \cdot c_{N}=C^{c}
$$

The 1.h.s. of (13d) gives total capacity cost when capacity is set according to (13b), which turns out to be equal to total toll revenues under the first-best pricing rule of (2a). This means that, whenever (13b) is satisfied but the toll rule deviates from (2a), optimal capacity choice

\footnotetext{
${ }^{1}$ More recently, Levinson and Gillen (1998) report a point estimate for the ratio between long-run average and marginal cost of 0.92 for auto, but 1.45 for single trucks and 1.96 for combination trucks, suggesting mild diseconomies for passenger cars but considerable economies for trucks.
} 
will result in an unbalanced budget. There will be a financial surplus if the toll exceeds the marginal external congestion cost (as for all instances of private pricing we have considered, as well as for the case of optimal pricing with an unpriced congested complement). There will be a deficit when the reverse holds (as for optimal pricing with an unpriced congested substitute). For a road in isolation - or, indeed, a road in an otherwise optimally managed network - equation (13d) confirms the self-financing theorem.

These results have implications for the potential of competitive auctions to achieve efficiency. At least when no subsidies are part of the auction, a competitive auction would drive profits to zero. For a road in isolation, and for which the constant-returns-to-scale assumptions are fulfilled, the optimal profit is zero, too. This means that there could be competitive auctions that would have the optimum road as an outcome. For a road with unpriced complements or substitutes, this would not generally be the case.

\section{Competitive auctions for an isolated road}

A competitive auction can be defined as one in which a sufficiently large number of noncooperative bidders are active, so that there is no scope for strategic behaviour and the bidders do not believe they will stand a chance of winning the auction when submitting a bid with a lower than their best score on the selection criterion used in the auction, because the bidders are sufficiently comparable in terms of efficiency. The assumption of a competitive auction allows a clean analysis of the performance of different selection criteria, without imperfections in the bidding process complicating the picture. Such imperfections would in reality of course be of potentially decisive importance, but the questions of to exactly what extent the performance of auction would be affected, and of whether the ranking of the different selection criteria would be systematically affected, are left for future research.

For a competitive auction thus defined, any selection criterion that can be improved upon as long as profits are positive would cause bidders to be pushed towards a zero-profit bid. We will call such criteria 'profit-exhausting'. All criteria we will consider in the sequel will be profit-exhausting. A somewhat unrealistic example of a criterion that would not be profit-exhaustive would be the criterion of 'social surplus' when an unpriced congested complement is available; compare equations (13d) and (10a) above.

Indeed, if information would be so complete that a meaningful auction with 'social surplus' as the criterion were possible, it would not be hard to define the optimal criterion for an auction. In practice, more easily observable criteria will however have to be used. The set that we will consider in our analysis is based on practical examples, earlier proposals in the literature, and on an attempt to find a relatively efficient criterion. The criteria to be considered are: a maximum bid for the right to build and operate the road ("Bid"), a maximum capacity supplied ("Cap"); a minimum toll charged ("Toll"); a minimum toll charged for a

pre-defined capacity ("Toll-cap"); and the maximization of patronage of the new capacity ("Pat").

If an auction is profit-exhausting, the occurrence of a 'winner's curse' is of course not inconceivable: the winning bid is from the party that holds the most optimistic expectations 
about market opportunities, and that therefore stands a considerable risk of below-projected patronage and hence net losses once operation commences. We will not formalize the existence of a distribution in expectations across potential bidders in our analysis. But one way of dealing with this problem in reality would be to ask bidders to supply, along with their bid, a detailed account of the predicted use levels, travel times, toll levels, and road design. This would allow verification of the plausibility of the travel times as a function of road characteristics (capacity) and patronage, as well as patronage as a function of travel time and toll level. For the latter test, existing transport network models could be used; and further insights can be obtained by comparing bids with each other. With a deviation above a certain threshold, the bid could be ignored to protect the bidder from a winner's curse, or clarification or revision could be demanded.

And finally, a credible and effective penalty should of course exist for underperformance compared to the bid, if wining. This penalty should be such that the firm should make a net loss from winning and underperforming, and might be coupled to the government obtaining the right to set toll levels when underperforming remains persistent.

\section{A numerical model: a single road}

We will illustrate the discussion of the various possible selection criteria using the results of a small numerical simulation model. The model is highly stylized, but nevertheless calibrated so as to be representative for a highway that is congested during peak times. The average user cost function is modelled according to the well-known BPR-formulation (Small, 1992):

$$
c(N / K)=\alpha \cdot t_{f} \cdot\left(1+\beta \cdot\left(\frac{N}{K}\right)^{\chi}\right)
$$

where $\alpha$ is a parameter reflecting the value of time (set at 7.5 in our model, according to conventional Dutch estimates), $t_{f}$ is a parameter reflecting the free-flow travel time (set at 0.5 , implying $60 \mathrm{~km}$ for a $120 \mathrm{~km} / \mathrm{hr}$ highway), and $\beta$ and $\chi$ are parameters that are set at 0.15 and 4 , respectively; conventional values for the BPR-function.

The units of capacity are chosen such that one conventional traffic lane would correspond to $K=1500$. This implies a doubling of travel times at a use level of around 2400 vehicles per hour. This is roughly in accordance to the flow at which, empirically, travel times double for a single highway lane and the maximum flow on a lane is reached (e.g. Small, 1992, Fig. 3.4, p. 66). A maximum flow, however, is not defined for BPR functions.

The price of capacity, $\gamma$, is set equal to 7 . With a unit of time of one hour, this parameter ought to reflect the hourly capital costs. To derive a value from empirical construction cost estimates, an assumption has to be made on whether the model aims to represent stationary traffic conditions throughout a day, or during peak hours only. Our parameterization concerns the latter. The value of 7 was then derived by dividing the estimated average yearly capital cost of one highway lane kilometre in The Netherlands ( $€ 0.2$ million) by 1100 (220 working days times 5 peak hours per working day; assuming two 
peaks) and next by 1500 (the number of units of capacity corresponding with a standard highway lane), and finally multiplying by 60 (the number of kilometres corresponding with a free-flow travel time of half an hour). Only welfare effects in peak hours are therefore considered in the numerical exercise, and it is assumed that off-peak travel is so modest that both the optimal off-peak toll and the marginal benefits of capacity expansion would be negligible. To maintain consistency, all selection criteria to be considered below, where relevant, would also apply to peak hours only. And finally, no relevant welfare effects arise outside the peak, and therefore no toll revenues are supposed to be raised.

Finally, it is assumed that a linear inverse demand function applies:

$D(N)=\delta_{0}-\delta_{1} \cdot N$

A choice of $\delta_{0}=31.21$ and $\delta_{1}=0.00462$, together with $K=3000$, produced a desired benchmark equilibrium where an equilibrium road use of $N=5000$ causes equilibrium travel time $t$ to be around two times the free-flow travel time $t_{f}$, while equilibrium demand elasticity $\varepsilon$ is equal to -0.35 . Because there are no toll revenues, profit $\pi$ is negative in the benchmark equilibrium. (This benchmark equilibrium will not be interpreted as some initial situation in the single-road analysis; that is, capacity will be allowed to become smaller than the benchmark level.)

\begin{tabular}{|c|c|c|c|c|c|c|}
\hline & Equilibrium & Optimum & Bid & Cap & Toll & Pat \\
\hline$t / t_{f}$ & 2.16 & 1.37 & 1.37 & 1.01 & n.r. ${ }^{b}$ & 1.37 \\
\hline$\varepsilon$ & -0.35 & -0.52 & -2.05 & -1.29 & $-\infty$ & -0.52 \\
\hline $\mathrm{K}$ & 3000.00 & 3530.77 & 1765.39 & 5807.29 & 0.00 & 3530.77 \\
\hline$\tau$ & 0.00 & 5.58 & 15.82 & 13.78 & n.r. ${ }^{b}$ & 5.58 \\
\hline $\mathrm{N}$ & 5000.00 & 4430.50 & 2215.25 & 2949.19 & 0.00 & 4430.50 \\
\hline c & 8.09 & 5.14 & 5.14 & 3.79 & n.r. ${ }^{b}$ & 5.14 \\
\hline$p$ & 8.09 & 10.72 & 20.96 & 17.57 & n.r. ${ }^{b}$ & 10.72 \\
\hline $\mathrm{D}$ & 8.09 & 10.72 & 20.96 & 17.57 & 31.21 & 10.72 \\
\hline$\pi$ & -21000.00 & 0.00 & $22686.70^{\mathrm{a}}$ & 0.00 & 0.00 & 0.00 \\
\hline$S$ & 36787.70 & 45373.40 & 34030.00 & 20104.80 & 0.00 & 45373.40 \\
\hline$\omega$ & 0 & 1 & -0.32 & -1.94 & -4.28 & 1.00 \\
\hline
\end{tabular}

a The figure shown in fact gives the bid. After making this bid, profit will become equal to zero.

${ }^{\mathrm{b}}$ Not relevant.

Table 1. Numerical results for a single road

The optimum configuration is depicted in the second column of Table 1. As expected, profits are exactly zero in the optimum. Optimal capacity $K$ is higher and optimal road use $N$ is lower than in the benchmark. As a result, travel times are lower (1.37 times the free-flow travel time).

Let us now turn to the various criteria for auctions. The first of these, Bid, forces the private operator to set the profit-maximizing toll and capacity identified in (4a) and (4b) (the net profit, after the sum promised in the bid has been paid, will of course be zero). This leads to a toll that is nearly three times as high as the optimal toll, and a capacity that is exactly half the optimal capacity (as can be expected with a linear demand function and constant long-run 
marginal cost). The final row in Table 1 shows an efficiency indicator $\omega$, which is for a particular equilibrium calculated as the social surplus in that equilibrium minus that in the benchmark, divided by social surplus in the optimum minus that in the benchmark. It therefore gives the share of first-best surplus gains relative to the benchmark that a particular auction achieves; a negative value denotes a surplus below the benchmark level. This is for example the case for the auction 'Bid'. The poor performance of this policy is in accordance with the rather pessimistic predictions of efficiency impacts of profit-maximizing congestion pricing in various earlier studies (e.g. Verhoef and Small, 2004).

A second auction, 'Cap', asks bidders to offer a capacity as large as possible. Because the toll is not restricted to be set optimally, the likely result is that capacity would exceed the optimal level: in the current numerical example it is nearly twice as large. The high capital costs are covered by a toll that is nearly as high as the profit maximizing toll, because it maximizes revenues given the capacity chosen. The resulting relatively small level of road use, in combination with the relatively large capacity, cause social surplus to be even lower than under 'Bid'.
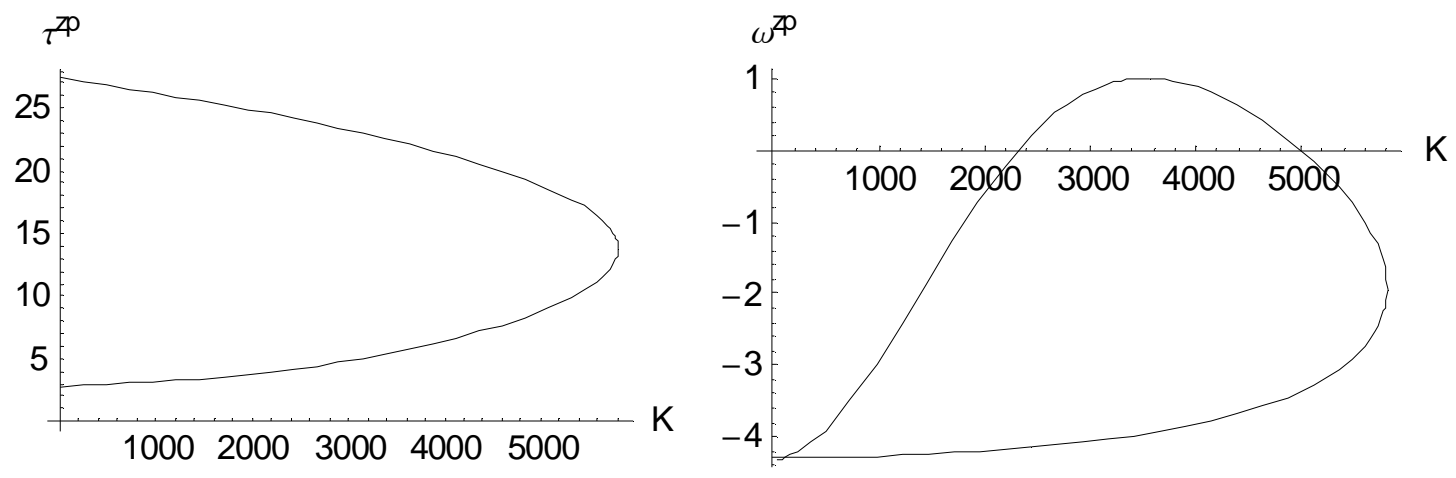

Figure 1. Zero-profit toll (left panel) and relative efficiency (right panel) as a function of capacity

A third auction, 'Toll', would award the concession to the bidder requiring the lowest toll. Although this criterion may seem reasonable at first sight, it will generally fail to produce an interior solution with a positive capacity. The left panel of Figure 1 illustrates why. It shows the zero-profit contour in the $K$ - $\tau$ space, which can be denoted $\tau^{z p}(K)$ : the correspondence between zero-profit tolls and capacity. First note that for all capacities below the maximum capacity that can be offered without a deficit (i.e., below the solution from auction 'Cap', around 5807 in the numerical model), there are in fact two toll levels that produce zero profits. For any capacity chosen, it is the lower of these two toll levels that would result with the criterion 'toll'. The area bounded by the contour $\tau^{z p}(K)$ and the vertical axis corresponds with positive profits; the area outside the contour with negative profits. A sufficient condition for backward-bending pattern to arise is that the inverses demand function should intersect 
both axes and that the elasticity of demand with respect to toll ${ }^{2}$, denoted $\varepsilon_{\mathcal{\tau}}$, should monotonously decrease (in absolute value) in $N$. All revenue levels below the maximum revenue for a certain capacity (at $\varepsilon_{\tau}=-1$ for that capacity) can then be realized as a higher-toll - lower-demand combination (the upper segment of the contour $\tau^{p p}(K)$ ) or as a lower-toll higher-demand combination (the lower segment of $\tau^{p}(K)$ ). Because the profit-maximizing toll for a certain capacity lies between the two zero-profit tolls, and because of our assumption of $\varepsilon_{\tau}$ decreasing monotonously in $N$, profit is increasing in $\tau$ for a given capacity on the lower segment, and decreasing in $\tau$ on the upper segment.

Near a zero capacity, the minimum zero-profit toll would be a declining function of capacity under rather general conditions. Under the constant-economies-of-scale assumptions, this would be true provided demand is not perfectly elastic. A sketch of a proof is as follows. Consider a certain capacity and a zero-profit toll below the revenue-maximizing toll for that capacity. Then imagine a simultaneous equi-proportional reduction of capacity and use. This would leave average cost $c$ unaltered. Therefore, to support this configuration as an equilibrium while marginal benefits $D$ have increased, $\tau$ should rise. This means that a profit will be made: capacity and use have fallen in the same proportion, so that maintaining zeroprofits would require the toll to remain at its original level, instead of rising. Because revenues are increasing in the toll level in this range, the toll should fall in order to return to zero profits. Hence, the minimum zero-profit toll is a declining function of capacity. As a result, the auction 'Toll' will not result in a winning bid with a positive capacity: bidders will be pushed towards bidding a zero capacity.

The right panel of Figure 1 depicts $\omega^{p}(K)$ : the correspondence between capacity and $\omega$ under zero-profit tolling. The upper segment of $\omega^{p p}(K)$ corresponds with the lower segment of $\tau^{z p}(K)$, and reversely. It shows that the outcome of the auction 'Toll' is the least efficient among the possible zero-profit combinations of $K$ and $\tau$. This is a general result under notperfectly-elastic demand, and is caused by the fact that under zero-profit tolling, marginal benefit is equal to average total cost (user cost and capital cost together). With a falling demand function, total benefit therefore exceeds total cost for any positive use level, and social surplus is always higher than in absence of the road (as resulting from 'Toll').

The first-best optimum is on the lower segment of the contour $\tau^{p}(K)$. An auction that would pre-specify the optimal capacity and next use the minimum toll as the criterion therefore would in principle be successful in achieving the first-best optimum. This auction 'Toll-cap' would be close to the one proposed by Engel, Fisher and Galetovic (1996), who propose an auction with as the criterion the minimization of the net present value of toll revenues (NPR) before the highway is to be transferred to the government. The setting of Engel et al. (1996) is rather different from that in this paper. They are primarily concerned with the promotion of cost-effectiveness in construction and the avoidance of renegotiation of contracts under demand uncertainty; but they treat the choice of capacity as exogenous and

\footnotetext{
${ }^{2}$ The elasticity of demand with respect to toll $\varepsilon_{\tau}$ differs from the conventional demand elasticity $\varepsilon$ because: (a) the toll $\tau$ differs from the generalized price $p=c+\tau$, and (b) $\mathrm{d} N / \mathrm{d} p \neq \mathrm{d} N / \mathrm{d} \tau$ (because $\mathrm{d} c / \mathrm{d} N \neq 0$ ).
} 
ignore the effect of toll setting on social welfare (in fact, they assume that the social objective is to minimize the expected value of tolls paid). Demand uncertainty and renegotiation are ignored in the present paper, but the impacts on social welfare are, in contrast, central. ${ }^{3}$

From that perspective, a number of observations can be made concerning Engel et al.'s NPR-auction. The first is that Figure 1 implies that over the relevant range of capacities, any target level of toll revenues below maximum revenues could be achieved by two toll levels, with strongly diverging welfare implications. A criterion that is phrased in terms of toll revenues - be it per-unit-of-time or in present value terms - cannot discriminate between these two tolls. As a consequence, there is no guarantee that whichever toll revenue is raised per unit of time, it is raised using the more efficient toll. In the numerical example, even for the optimal capacity would the higher-toll equilibrium produce only very limited benefits compared to the no-road situation ( $\omega$ is close to -4 ). A second observation is that the NPRauction does not direct the operator towards an optimal toll revenue per unit of time: it is only the net present value that matters. If after transferring the road to the government, tolling is discontinued, the auction may cause pricing to be non-optimal both before and after the transfer. It is therefore uncertain whether an NPR-auction would indeed produce an optimal outcome, especially when social surplus would be the social objective.

The final auction we consider is 'Pat': the auction that awards the concession to the operator that offers the highest patronage. The final column in Table 1 shows that the outcome of this auction coincides with the first-best optimum. Again, this result can be expected to carry over to more general settings, as long as the constant-returns-to-scaleassumptions are fulfilled. The intuition is as follows. First, observe that the maximization of demand requires the minimization of generalized price, and hence of $\tau+c$. Next, zero profits imply that $\tau$ is equal to capacity cost per user, so that the generalized prize becomes $C^{c} / N+c$. Minimizing this with respect to $K$, as the bidder would need to do to maximize $N$, yields (for any positive $N$ ) an expression that is equal to (4b): the optimality condition for optimal capacity as a function of road use $N$. Because of the constant-returns-to-scale assumptions, the generalized price therefore coincides with the long-run marginal cost (user cost and capacity cost jointly), so that also $N$ is optimized. And the joint occurrence of an optimal $N$ and an optimal $K(N)$ secures achievement of the first-best optimum.

The perhaps counter-intuitive conclusion is therefore that, provided the constantreturns-to-scale conditions are fulfilled, the auction that maximizes social surplus is the one that maximizes traffic flow.

\section{Second-best network effects}

An important simplification of the above analysis concerns the neglect of network effects. This is acceptable when studying a road in isolation, or under the hypothetical assumption of

\footnotetext{
${ }^{3}$ Cost-effectiveness in construction is not considered explicitly in this paper, and firms are assumed to always operate on the capacity cost function $C^{c}$. A competitive profit-exhausting auction would, however, always secure cost-effectiveness in construction. Explicit consideration of cost-effectiveness in construction would therefore not affect the conclusions.
} 
first-best pricing throughout the rest of the network. It can also be considered instructive to deliberately ignore network complications, because doing so allows concentration on the primary efficiency impacts of the various auctions, independent of second-best network spillovers. But network effects are likely to be important in reality, and may, as we shall see below, have significant impacts on the performance of auctions. To maintain focus and keep the exposition transparent, we will consider two very simple networks in what follows, which would represent the most important types of second-best network issues that could arise. Section 4.1 considers the situation where an unpriced perfect substitute for the new road is available (i.e., a parallel road), while Section 4.2 considers an unpriced complement (i.e., a serial road).

\subsection{Unpriced substitute}

The existence of an unpriced substitute road naturally reduces the potential profitability of the new road. This effect can be substantial, which is illustrated by the fact that when interpreting the rather heavily congested benchmark road from the previous section as pre-existing initial capacity, no profitable capacity-toll combination for additional, priced capacity appears to be possible. Also the second-best optimum, for which the capacity of and toll on the tolled new parallel is optimized under the constraint that initial capacity remains untolled, consequently produces a financial deficit. The results in Table 2 show that only $7 \%$ of the capacity cost for the second-best optimal toll road would be covered by the revenues from the second-best toll.

\begin{tabular}{lrrr}
\hline & Equilibrium & \multicolumn{1}{c}{ Optimum } & Second-best \\
$\mathrm{K}_{U}$ & 3000.00 & 3000.00 & 3000.00 \\
$\mathrm{~K}_{\mathrm{T}}$ & 0.00 & 530.77 & 1227.48 \\
$\mathrm{~K}$ & 3000.00 & 3530.77 & 4227.48 \\
$\tau_{U}$ & 0.00 & 5.58 & 0.00 \\
$\tau_{T}$ & 0.00 & 5.58 & 0.40 \\
$\mathrm{~N}_{U}$ & 5000.00 & 3764.47 & 4010.11 \\
$\mathrm{~N}_{T}$ & 0.00 & 666.03 & 1540.27 \\
$\mathrm{~N}$ & 5000.00 & 4430.50 & 5550.38 \\
$\mathrm{C}_{U}$ & 8.09 & 5.14 & 5.55 \\
$\mathrm{C}_{T}$ & 8.09 & 5.14 & 5.14 \\
$\pi_{T}$ & 0.00 & 0.00 & -7974.39 \\
$\mathrm{~S}$ & 36787.70 & 45373.40 & 42235.80 \\
$\omega$ & 0 & 1 & 0.63 \\
Cost & & & 0.07 \\
coverage & & & \\
\hline
\end{tabular}

Table 2. Numerical results for an unpriced substitute: original parameterization

Under this parameterization, no bids can be expected in an auction if it does not include the possibility of subsidies. Ubbels and Verhoef (2004) explore the possibilities for and properties of auctions with subsidies. In this paper, we do not consider such auctions, motivated by the observation that if the required subsidy would be so large (93\% of the construction costs in the numerical example), a government would most likely prefer to carry $100 \%$ of the 
construction costs and keep the road in public hands altogether. An auction that raises only $7 \%$ of the construction cost while meaning loss of (direct) control over the highway (toll) does not seem to be a very attractive option when social surplus maximization is the overall objective.

In order to get an idea of the performance of zero-subsidy auctions in the presence of an unpriced substitute, the parameterization has to be adjusted, so as to create the possibility of zero-profit bids with positive capacity. This was achieved in the numerical model by reducing the initial capacity from 3000 to 1500 . As a result, the benchmark equilibrium travel time becomes 4.3 times as high as the free-flow travel time. For such a heavily congested road, zero-profit bids for additional priced capacity do become possible, and the results for the different criteria are shown in Table 3.

The first-best optimum (for which pricing on both roads is allowed) is of course equivalent to that for the road in isolation. Because initial unpriced capacity is relatively small, the second-best equilibrium achieves a relative efficiency of $\omega=0.91$, which is substantial. However, because of the second-best nature of this equilibrium, the toll is set according to equation (6a), producing a toll that is only $16 \%$ of the first-best toll. As a result, a substantial deficit will occur on the operation of the tolled road: the cost coverage for the new road in the second-best equilibrium is only $16 \%$, despite the fact that tolled capacity makes up nearly two thirds of total capacity. Again, it would seem more attractive to keep the road in public hands than to design an auction that would, if successful in reproducing the second-best optimum, require a subsidy of $84 \%$ of total construction cost.

\begin{tabular}{|c|c|c|c|c|c|c|c|c|}
\hline & Equilibrium & Optimum & $\begin{array}{l}\text { Second- } \\
\text { best }\end{array}$ & Bid & Cap & Toll & Pat & $\begin{array}{l}\text { Second- } \\
\text { best zp. }\end{array}$ \\
\hline $\mathrm{Ku}_{\mathrm{u}}$ & 1500.00 & 1500.00 & 1500.00 & 1500.00 & 1500.00 & 1500.00 & 1500.00 & 1500.00 \\
\hline $\mathrm{K}_{\mathrm{T}}$ & 0.00 & 2030.77 & 2649.79 & 633.25 & 1430.90 & 0.00 & 1287.74 & 1287.74 \\
\hline $\mathrm{K}$ & 1500.00 & 3530.77 & 4149.79 & 2133.25 & 2930.90 & 1500.00 & 2787.74 & 2787.74 \\
\hline$\tau_{U}$ & 0.00 & 5.58 & 0.00 & 0.00 & 0.00 & 0.00 & 0.00 & 0.00 \\
\hline$\tau_{T}$ & 0.00 & 5.58 & 0.87 & 8.27 & 6.95 & n.r. ${ }^{b}$ & 5.58 & 5.58 \\
\hline $\mathrm{N}_{U}$ & 3251.72 & 1882.24 & 2124.34 & 3053.85 & 2868.88 & 3251.72 & 2814.60 & 2814.60 \\
\hline $\mathrm{N}_{\mathrm{T}}$ & 0.00 & 2548.26 & 3325.02 & 794.61 & 1441.85 & 0.00 & 1615.90 & 1615.90 \\
\hline $\mathrm{N}$ & 3251.72 & 4430.50 & 5449.36 & 3848.46 & 4310.73 & 3251.72 & 4430.50 & 4430.50 \\
\hline cu & 16.17 & 5.14 & 6.01 & 13.41 & 11.28 & 16.17 & 10.72 & 10.72 \\
\hline Ст & 16.17 & 5.14 & 5.14 & 5.14 & 4.33 & n.r. ${ }^{b}$ & 5.14 & 5.14 \\
\hline$\pi_{T}$ & 0.00 & 0.00 & -15661.60 & $2138.11^{a}$ & 0.00 & 0.00 & 0.00 & 0.00 \\
\hline S & 13941.20 & 45373.40 & 42480.00 & 25873.10 & 32453.50 & 13941.20 & 34873.40 & 34873.40 \\
\hline$\omega$ & 0 & 1 & 0.91 & 0.38 & 0.59 & 0.00 & 0.67 & 0.67 \\
\hline $\begin{array}{l}\text { Cost } \\
\text { coverage }\end{array}$ & & & 0.16 & & & & & \\
\hline
\end{tabular}

Table 3. Numerical results for an unpriced substitute: adjusted parameterization

If insufficient public funds are available to finance this investment, the question rises of how attractive zero-profit roads might be. The final column in Table 3 shows the second-best 
optimum under an additional zero-profit constraint; so, the best achievable benchmark outcome for zero-profit auctions. The toll is substantially higher and capacity lower than in the second-best optimum. However, $\omega$ still reaches a level of 0.67 when the zero-profit constraint is added to the second-best problem. The levels of $\tau_{T}$ and $c_{T}$ are the same as for the first-best equilibrium, which is caused by the facts that the auction induces the operator to minimize total cost for any given $N_{T}$ while keeping capacity self-financing. This means selecting the same $K / N$ ratio, and the same $c$ and $\tau$, as for the first-best optimum.

The auction 'Pat' again achieves the second-best optimum (under the zero-profit constraint). Maximizing $N_{T}$ under a zero profit constraint requires minimization of average user cost plus capital cost per user. Because of the network equilibrium condition, the minimization of the generalized price on road $T$ implies that average user cost on road $U$ are also minimized. $N_{U}$, and $N_{T}+N_{U}$, are therefore maximized - and so is therefore total benefit. ${ }^{4}$ For a given $K_{U}$, and given $\tau_{U}=0$, these are the same conditions that define the second-best zero-profit equilibrium.

We can be brief on the other criteria. 'Bid' still does not perform very good ( $\omega=0.38)$, which is caused by the large discrepancy between the revenue-maximizing and the surplusmaximizing second-best toll; compare (6a) and (8a). 'Cap' performs relatively good $(\omega=0.59)$, which is caused by the fact that there is not much scope to expand capacity of the new road beyond the second-best zero-profit level without running into losses. And 'Toll', as before, will not result in the supply of a positive capacity. Note that all $\omega$ s are positive. The reason is that road users as a group can only benefit from the supply of additional capacity that is to be used voluntarily, while profits will be zero. Social surplus, therefore, can only increase.

The absence of subsidization possibilities combined with the absence of pricing on initial capacity causes the maximum achievable welfare gains to be around two thirds of those from first-best pricing and capacity choice. The size of the relative loss, around one third in this example, evidently depends on the assumed initial conditions, and may in some cases become so large that the overall efficiency gain from the auction becomes unacceptably small. Would there, in such cases, be a possibility to enhance the social benefits from the auction by changing its set up? One possible strategy, based on the observation that the source of the reduced efficiency gains is the existence of initial unpriced capacity, would be to stipulate that the winning bidder will have to buy the existing road against the best estimate of the current construction costs for the same capacity, and to allow the winning bidder to apply a congestion toll on this existing capacity. Provided the implied capital cost per unit of capacity for the initial capacity are the same as a bidder's cost per unit of new capacity, and provided the initial capacity is smaller than the capacity a bidder would choose in an auction, he will in fact face the same problem as for the road in isolation. The auction 'Pat' would then again

\footnotetext{
${ }^{4}$ The outcome of the auction 'Pat' appears to be independent of whether it is the patronage of the new capacity $\left(N_{T}\right)$ or of both roads together $\left(N_{T}+N_{U}\right)$ that is used as the criterion. Maximizing $N_{T}$ through minimizing the generalized price on that road also maximizes $N_{U}$, because the generalized prices on both roads will be equalized in equilibrium.
} 
achieve the first-best optimum. Therefore, there certainly may be ways to avoid particularly unattractive network spill-overs through auctions, by making the compulsory purchase of the associated links part of the concession.

\subsection{Unpriced complement}

The logical companion problem to the existence of an unpriced substitute is the existence of an unpriced complement. Table 4 shows the numerical results, for which in order to maintain comparability, the assumption was made that half the road's length would remain unpriced and at the benchmark capacity (3000) so as to function as the unpriced complement, while the other half would be subject to the auction.

\begin{tabular}{|c|c|c|c|c|c|c|c|c|}
\hline & Equilibrium & Optimum & $\begin{array}{c}\text { Second- } \\
\text { best }\end{array}$ & Bid & Cap & Toll & Pat & $\begin{array}{l}\text { Second- } \\
\text { best zp. }\end{array}$ \\
\hline $\mathrm{K}_{\mathrm{U}}$ & 3000.00 & 3530.77 & 3000.00 & 3000.00 & 3000.00 & 3000.00 & 3000.00 & 3000.00 \\
\hline $\mathrm{K}_{\mathrm{T}}$ & 3000.00 & 3530.77 & 3276.57 & 2005.84 & 11440.40 & 0.00 & 3816.79 & 3816.83 \\
\hline$\tau_{U}$ & 0.00 & 2.79 & 0.00 & 0.00 & 0.00 & n.r. ${ }^{b}$ & 0.00 & 0.00 \\
\hline$\tau_{\top}$ & 0.00 & 2.79 & 6.76 & 14.98 & 14.07 & n.r. ${ }^{b}$ & 2.79 & 2.79 \\
\hline$\tau$ & 0.00 & 5.58 & 6.76 & 14.98 & 14.07 & $n . r^{b}$ & 2.79 & 2.79 \\
\hline$N$ & 5000.00 & 4430.50 & 4111.52 & 2516.98 & 2845.70 & 0.00 & 4789.46 & 4789.46 \\
\hline $\mathrm{Cu}$ & 4.05 & 2.57 & 2.87 & 2.01 & 2.10 & n.r. ${ }^{b}$ & 3.70 & 3.70 \\
\hline $\mathrm{C}_{\mathrm{T}}$ & 4.05 & 2.57 & 2.57 & 2.57 & 1.88 & n.r. ${ }^{b}$ & 2.57 & 2.57 \\
\hline c & 8.09 & 5.14 & 5.44 & 4.59 & 3.98 & n.r. ${ }^{b}$ & 6.27 & 6.27 \\
\hline$\pi_{\mathrm{T}}$ & -10500.00 & 12357.70 & 16318.40 & $30690.60^{\mathrm{a}}$ & 0.00 & 0.00 & 0.00 & 0.00 \\
\hline S & 36787.70 & 45373.40 & 44893.50 & 34834.40 & 8218.64 & -10500.00 & 42523.50 & 42523.50 \\
\hline$\omega$ & 0 & 1 & 0.94 & -0.23 & -3.33 & -5.51 & 0.67 & 0.67 \\
\hline $\begin{array}{l}\text { Cost } \\
\text { coverage }\end{array}$ & & & 2.42 & & & & & \\
\hline
\end{tabular}

Table 4. Numerical results for an unpriced complement

Equations (10ab) already showed that there will be a financial surplus in the second-best optimum, because the second-best optimal toll also internalizes the congestion externality on the unpriced complement. The third column in Table 4 shows that in the numerical example, the revenues will consequently be more than twice as large as the capacity cost. The secondbest optimum with an additional zero-profit constraint defines the best possible outcome for profit-exhausting auctions. The final column in Table 4 shows that $\omega$ drops to 0.67 (the similarity with the unpriced-substitute case in Table 3 is a coincidence). Again, the auction 'Pat' is the only auction that reproduces the second-best zero-profit equilibrium: maximization of $N$ under a zero-profit constraint apparently again implies maximization of the social surplus under that same constraint - given the inability to adjust $K_{U}$. The reason is that under zero-profit pricing the generalized price is equal to average total cost (that is: average user cost and per-user capital cost for link $T$ jointly; capital cost for link $U$ are ignored but are fixed anyway). Social surplus is therefore given by consumer surplus, and this is maximized when $N$ is maximized by minimizing the generalized price. 
The relative ranking of 'Bid' and 'Cap' has reversed compared to the unpricedsubstitute case. 'Bid' leads to the profit maximizing outcome and therefore avoids the potentially substantial overinvestment in link $T$ 's capacity that the revenues from implicit congestion pricing of link $U$ allow. Indeed, $K_{T}$ could be expanded up to more than three times its second-best level without running into losses; compare ' $C a p$ ' and 'Second-best' in Table 4. Because 'Cap' aggravates this distortion, its efficiency is relatively low. 'Toll', finally, again suffers from the problem of not producing a positive equilibrium capacity.

Apart from making the compulsory purchase of the unpriced link part of the auction, as for the unpriced-substitute case, a simpler solution to the problem of over-investment appears possible in this case, and that would be to inform the bidders that they will be charged a toll equal to the marginal external congestion cost on link $U$ for every user passing that link. This would take away the 'excess profits' and leave the private bidders facing the same conditions as in Section 3, meaning that 'Pat' would again reproduce the optimum.

\section{Conclusion}

Shortage of funds for road expansion, political unacceptability of public road pricing, and perhaps expectations of higher efficiency from private operations may all be factors that cause the private provision of toll roads to become an attractive option to cope with growing traffic congestion. Concessions for private road operation will typically be auctioned. This paper showed that the selection criterion used in such auctions may have a decisive impact on the efficiency of the resulting winning bid. A bid for the right to build and operate the road pushes the bidders towards a profit-maximizing design, which will typically be quite different from a surplus-maximizing road. The maximization of capacity typically leads to excessive capacity, and a revenue-maximizing toll given that capacity; both reducing surplus below achievable levels. The minimization of tolls pushes bidders towards a zero capacity, unless capacity is set a priori. The minimization of toll revenues does the same, and in addition suffers from the fact that there may be multiple toll levels that, given a capacity, yield the same revenue but differ strongly in welfare impacts. However, an auction that asks to maximize patronage appeared to reproduce the first-best road in absence of network spillovers and under constant-economies-of-scale assumptions, and the second-best zero-profit road with network spill-overs.

Many important questions that need further consideration can be identified. A first one is whether a credible and efficient penalty system can be thought of that would guarantee the winning bidder to live up to the bid. A second one is whether a mechanism can be developed to cope with demand uncertainty and avoid renegotiation of contracts. A third one involves extension of the current analysis to larger, ideally 'generalized' networks, and multiple time periods (notably peak - off-peak). A fourth one involves strategic behaviour and interactions during the bidding process. The list could probably be extended easily, and illustrates that there is still sufficient potential for future research. 


\section{References}

Arnott, R., A. de Palma and R. Lindsey (1993) "A structural model of peak- period congestion: a traffic bottleneck with elastic demand" American Economic Review 83 (1) 161-179.

Arnott, R. and M. Kraus (1998) "Self-financing of Congestible Facilities in a Growing Economy". In: D. Pines, E. Sadka and I. Zilcha (eds.) (1998) Topics in Public Economics: Theoretical and Applied Analysis Cambridge University Press, Cambridge UK, pp. 161-184.

Edelson, N.E. (1971) "Congestion tolls under monopoly" American Economic Review 61 (5) 872-882.

Engel, E., R. Fisher and A. Galetovic (1996) "Highway franchising: pitfalls and opportunities" American Economic Review, Papers and Proceedings 87 (2) 68-72.

Lévy-Lambert, H. (1968) "Tarification des services à qualité variable: application aux péages de circulation" Econometrica 36 (3-4) 564-574.

Mills, D.E. (1981) "Ownership arrangements and congestion-prone facilities" American Economic Review, Papers and Proceedings 71 (3) 493-502.

Mohring, H. (1985) "Profit maximization, cost minimization, and pricing for congestion-prone facilities" Logistics and Transportation Review 21 27-36.

Mohring, H. and M. Harwitz (1962) Highway Benefits: An Analytical Framework Northwestern University Press, Evanston Il.

Small, K.A. (1992). Urban Transportation Economics. Fundamentals of Pure and Applied Economics. Harwood, Chur.

Ubbels, B. and E.T. Verhoef (2004) "Auctioning concessions for private roads" Discussion paper TI 2004-008/3, Tinbergen Institute, Amsterdam-Rotterdam.

Verhoef, E.T. (2002a) "Second-best congestion pricing in general static transportation networks with elastic demands" Regional Science and Urban Economics 32 281-310.

Verhoef, E.T. (2002b) "Second-best congestion pricing in general networks: heuristic algorithms for finding second-best optimal toll levels and toll points" Transportation Research 36B 707-729.

Verhoef, E.T., P. Nijkamp and P. Rietveld (1996) "Second-best congestion pricing: the case of an untolled alternative" Journal of Urban Economics 40 (3) 279-302.

Verhoef, E.T. and K.A. Small (2004) "Product differentiation on roads: second-best congestion pricing with heterogeneity under public and private ownership" Journal of Transport Economics and Policy 38 (1) 127-156.

Yang, H. and Q. Meng (2002) "A note on 'Highway pricing and capacity choice in a road network under a build-operate-transfer scheme"" Transportation Research 36A 659-663. 